\title{
Clinical Stage IV Esophageal Adenocarcinoma AJCC v8
}

National Cancer Institute

\section{Source}

National Cancer Institute. Clinical Stage IV Esophageal Adenocarcinoma A/CC V8. NCI

Thesaurus. Code C133408.

Stage IV includes: IVA: (T1-4a, N2, M0); (T 4b, N0-2, M0); (Any T, N3, M0); IVB: (Any T, Any N, M1). T1: T umor invades the lamina propria, muscularis mucosae, or submucosa. T2: Tumor invades the muscularis propria. T3: Tumor invades adventitia. T4a: Tumor invades the pleura, pericardium, azygos vein, diaphragm, or peritoneum. T4b: Tumor invades other adjacent structures, such as the aorta, vertebral body, or airway. N0: No regional lymph node metastasis. N1: Tumor with metastasis in one or two regional lymph nodes. N2: T umor with metastasis in three to six regional lymph nodes. N3: Tumor with metastasis in seven or more regional lymph nodes. M0: No distant metastasis. M1: Distant metastasis. (AJCC 8th ed.) 